\title{
Haloacetylation Driven Transformation of Sandwich Herringbone to Lamellar/Columnar Packing in Pyrene
}

\author{
P. S. Salini, ${ }^{\perp}$ Shinaj K. Rajagopal $\perp$ and Mahesh Hariharan*
}

School of Chemistry, Indian Institute of Science Education and Research Thiruvananthapuram, CET Campus, Sreekaryam, Thiruvananthapuram, Kerala, INDIA 695016

E-mail: mahesh@iisertvm.ac.in or mahesh.hrn@gmail.com

\section{Supporting Information}

\begin{tabular}{|c|c|c|}
\hline No & Contents & Page \\
\hline 1 & Materials and methods. & 2 \\
\hline 2 & Scheme $\mathbf{S 1}$ showing the syntheses of $1,3-\mathrm{CP}$ and $1,8-\mathrm{CP}$. & 3 \\
\hline 3 & Scheme $\mathbf{S 2}$ showing the syntheses of $1,3-\mathrm{BP}$ and $1,8-\mathrm{BP}$. & 3 \\
\hline 4 & Scheme $\mathbf{S 3}$ showing the syntheses of 1,3-FP and 1,8-FP. & 3 \\
\hline 5 & Scheme $\mathbf{S} 4$ showing the syntheses of 1,3 -IP and 1,8-IP. & 3 \\
\hline 6 & $\begin{array}{l}\text { Table S1. Shows the intramolecular interactions in a) } 1,3-\mathrm{XP} \text { and b) } 1,8-\mathrm{XP} \text { as } \\
\text { visualised through Mercury CSD } 3.8 \text {. }\end{array}$ & 4 \\
\hline 7 & $\begin{array}{l}\text { Table S2. Calculated topological properties of the electron density for the } \\
\text { intermolecular interaction in XP. }\end{array}$ & 5 \\
\hline 8 & Figure S1. Single crystal X-ray structure of XPs. & 5 \\
\hline 9 & $\begin{array}{l}\text { Figure S2. Decrease in the intramolecular dihydrogen distance in } 1,8 \text {-XP compared } \\
\text { to } 1,8-\mathrm{AP}\end{array}$ & 6 \\
\hline 10 & $\begin{array}{l}\text { Figure S3. Shows the decrease in the interplanar distance between pyrene units in } \\
1,3-\mathrm{XP} \text {. }\end{array}$ & 6 \\
\hline 11 & $\begin{array}{l}\text { Figure S4. Figure S4. Calculated ESP maps of representative monomers of A) } 1,3- \\
\mathrm{XP} \text { and B) } 1,8-\mathrm{XP} \text { from crystal structure. All maps used consistent surface potential } \\
\text { ranges }[-4.75 \mathrm{e}-2 \text { au (red) to } 4.75 \mathrm{e}-2 \text { au (blue) }] \text { and an isovalue of } 0.000400 \mathrm{au} \text {. }\end{array}$ & 7 \\
\hline 12 & Figure S5. Intermolecular $\mathrm{C}\left(\mathrm{sp}^{2}\right)-\mathrm{H} \bullet \cdot \mathrm{Br}$ interaction in $1,3-\mathrm{BP}$. & 7 \\
\hline 13 & $\begin{array}{l}\text { Figure S6. Shows QTAIM electron density map of } 1,3-\mathrm{IP} \text {, arrows indicate the } \\
\text { existence of intermolecular I } \cdots \pi \text { contacts. }\end{array}$ & 7 \\
\hline 14 & $\begin{array}{l}\text { Figure S7. Shows QTAIM electron density map of } 1,8 \text {-FP, arrows indicate the } \\
\text { existence of intermolecular C } \cdots \text { F interactions. }\end{array}$ & 8 \\
\hline 15 & $\begin{array}{l}\text { Figure S8. Shows the decrease in the interplanar distance between pyrene units in } \\
1,8-\mathrm{XP} \text {. }\end{array}$ & 8 \\
\hline
\end{tabular}




\section{Materials and methods}

All chemicals were obtained from commercial suppliers and used as received without further purification. All reactions were carried out in oven-dried glassware prior to use and wherever necessary, were performed under dry nitrogen in dried, anhydrous solvents using standard gastight syringes, cannulae, and septa. Solvents were dried and distilled by standard procedures. TLC analysis were performed on precoated aluminum plates of silica gel $60 \mathrm{~F} 254$ plates $(0.25 \mathrm{~mm}$, Merck) and developed TLC plates were visualized under short and long wavelength UV lamps. Flash column chromatography was performed using silica gel of 200-400 mesh employing a solvent polarity correlated with the TLC mobility observed for the substance of interest.

X-ray Crystallography: High-quality specimens of appropriate dimensions were selected for the Xray diffraction experiments. Crystallographic data collected are presented in the supplementary information. Single crystals were mounted using oil (Infineum V8512) on a glass fibre. All measurements were made on a CCD area detector with graphite monochromated Mo Ka radiation. The data was collected using Bruker APEXII detector and processed using APEX2 from Bruker. All structures were solved by direct methods and expanded using Fourier techniques. The non-hydrogen atoms were refined anisotropically. Hydrogen atoms were included in idealized positions, but not refined. Their positions were constrained relative to their parent atom using the appropriate HFIX command in SHELXL-97. The full validation of CIFs and structure factors of XPs derivatives were performed using the CheckCIF utility and found to be free of major alert level. 3D structure visualization and the exploration of the crystal packing of XPs were carried out using Mercury 3.1.

\section{Computational methods}

Quantum Theory of Atoms in Molecules (QTAIM): The wave function for XPs were obtained employing the geometries taken from the crystal structure using Gaussian set of codes at B3LYP/6$311 \mathrm{G}^{* *^{++}}$level. ${ }^{1}$ Quantum theory of atoms in molecules (QTAIM) analysis helps to understand the description of interatomic interaction in the single crystal X-ray structure. A bond is defined along the bond line between two nuclei, called a bond path, along which electron density is concentrated. The bond critical point (BCP) is a point along the bond path at the interatomic surface, where the shared electron density reaches a minimum. The physical characteristics of the BCPs [the electron density at $\mathrm{BCP}, \rho\left(r_{\mathrm{BCP}}\right)$, and its Laplacian, $\left.\nabla^{2} \rho\left(r_{\mathrm{BCP}}\right)\right]$ reveal the approximate measure of the amount of electron density built up in the bonding region and as such could be taken as characteristic of the bond. When $\nabla^{2} \rho\left(r_{\mathrm{BCP}}\right)<0$ and is large in magnitude, $\rho\left(r_{\mathrm{BCP}}\right)$ is also large which means that there is a concentration of electronic charge in the internuclear region. This is also an indication of a sharing of electronic charge between both nuclei that defines the covalent (polar) bond. When $\nabla^{2} \rho\left(r_{\mathrm{BCP}}\right)<0$ there is a depletion of electronic charge in the internuclear region. Using the AIM 2000 software package, the electron density was integrated over atomic basins according to the quantum theory of atoms in molecules using PROAIM, and thus the BCP data and the molecular graphs were obtained.

Electrostatic Surface Potential: Electrostatic surface potential map illustrate the charge distributions of molecules three dimensionally. These maps allow us to visualize variably charged regions of a molecule. Knowledge of the charge distributions can be used to determine how molecules interact with one another. Gaussian supports the cube keyword to generate the cubes separately from the formatted checkpoint file using the cubegen utility program. This allows for the generation of electrostatic surface potential mapping of the molecule.

Hirshfeld Analysis: Important intermolecular interactions within the crystal structure of XPs were identified through Hirshfeld surface analysis using Crystal Explorer 3.0. The Hirshfeld surface is defined as a set of points in 3D space where the ratio of promolecule and procrystal electron densities is equal to 0.5 . The exploration of intermolecular contacts is provided by mapping normalized contact distances $\left(d_{\text {norm }}\right)$, which is a function of a closest distance from the point to the nuclei interior $\left(d_{\mathrm{i}}\right)$ and exterior $\left(d_{\mathrm{e}}\right)$ to the surface as well as on the van der Waals radii $\left(\mathrm{r}^{\mathrm{vdw}}\right)$. 2D fingerprint which were generated by deriving from the Hirshfeld surface by plotting the fraction of points on the surface as the fuction of $d_{\mathrm{i}}$ and $d_{\mathrm{e}}$ which provide a visual summary of intermolecular contacts within the crystal. 

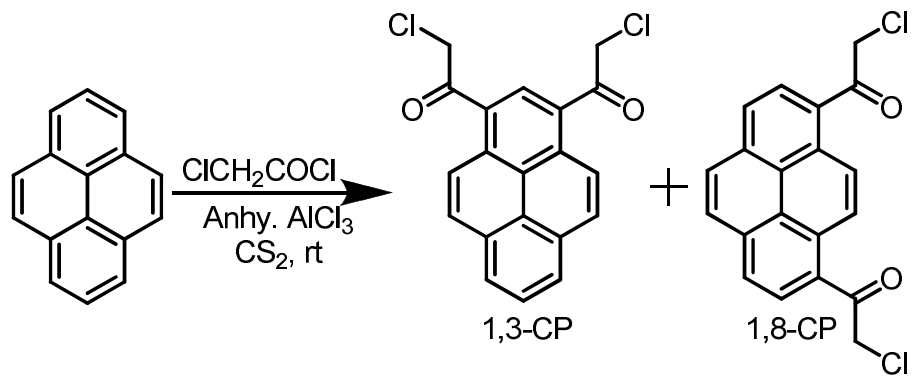

Scheme S1. Synthesis of 1,3- and 1,8-Bis(chloroacetyl)pyrene (1,3-CP and 1,8-CP).

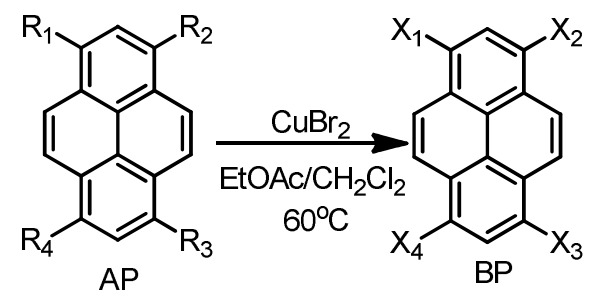

$$
\begin{aligned}
& R_{1}=R_{2}=\text { a d } R_{3}=R_{4}=H ; X_{1}=X_{2}=\text { w } \\
& R_{2}=R_{3}=\text { a d } R_{1}=R_{4}=H ; X_{1}=X_{4}=\text { N } B r X_{2}=X_{3}=H(1,8-B P)
\end{aligned}
$$

Scheme S2. Synthesis of 1,3- and 1,8-Bis(bromoacetyl)pyrene (1,3-BP and 1,8-BP).

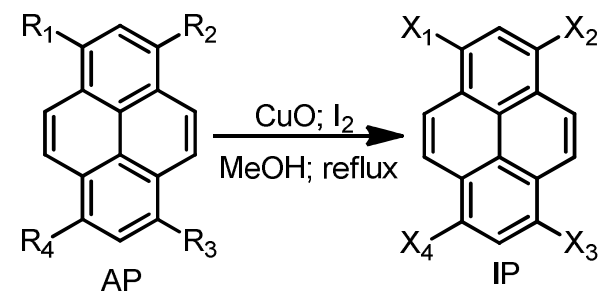

$$
\begin{aligned}
& R_{1}=R_{2}=\text { ल } R_{3}=R_{4}=H ; X_{1}=X_{2}=\text { m } \\
& R_{2}=R_{3}=\text { a d } R_{1}=R_{4}=H ; X_{2}=X_{3}=\text { a d I } X_{1}=X_{4}=H(1,8-I P)
\end{aligned}
$$

Scheme S3. Synthesis of 1,3- and 1,8-Bis(iodoacetyl)pyrene (1,3-IP and 1,8-IP).

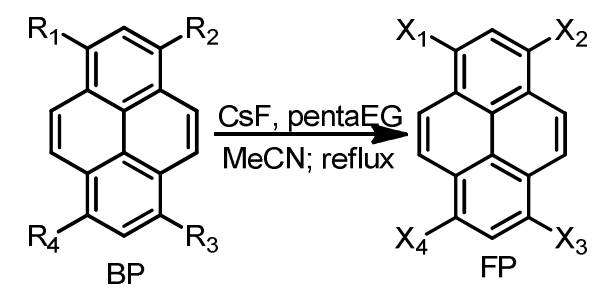

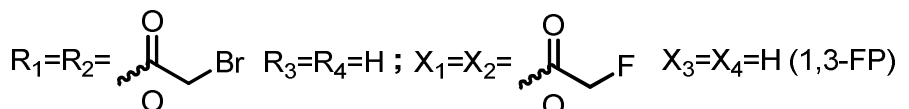

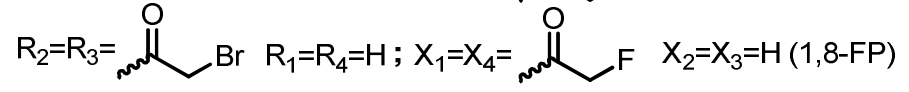

Scheme S4. Synthesis of 1,3- and 1,8-Bis(fluroacetyl)pyrene (1,3-FP and 1,8-FP). 
Table S1. Shows the intramolecular interactions in a) 1,3-XP and b) 1,8-XP as visualised through Mercury CSD 3.8.

\begin{tabular}{|c|c|c|}
\hline & Interaction & $d(\AA)$ \\
\hline \multirow{4}{*}{ 1,3-FP } & $\mathrm{H} 1 \bullet \bullet H 3$ & 2.068 \\
\hline & $\mathrm{H} 1 \bullet \bullet \mathrm{H}_{4}$ & 2.208 \\
\hline & $\mathrm{H} 1 \bullet \bullet \mathrm{H}_{2}$ & 2.268 \\
\hline & $\mathrm{O} 1 \bullet \bullet \mathrm{H} 7$ & 2.205 \\
\hline \multirow{8}{*}{$1,3-\mathrm{CP}$} & $\mathrm{O} 2 \bullet \bullet \bullet \mathrm{H} 6$ & 2.505 \\
\hline & $\mathrm{H} 1 \bullet \bullet \mathrm{H}_{2}$ & 2.362 \\
\hline & $\mathrm{H} 1 \bullet \bullet \bullet H 3$ & 2.051 \\
\hline & $\mathrm{H} 1 \bullet \bullet \bullet$ & 2.208 \\
\hline & $\mathrm{H} 1 \bullet \bullet \bullet \mathrm{H} 5$ & 2.162 \\
\hline & $\mathrm{O} 1 \bullet \bullet \mathrm{H}_{7}$ & 2.160 \\
\hline & $\mathrm{O} 2 \bullet \bullet \bullet \mathrm{H} 6$ & 2.179 \\
\hline & $\mathrm{H} 1 \bullet \bullet \mathrm{H} 3$ & 1.964 \\
\hline \multirow{3}{*}{ 1,3-BP } & $\mathrm{H} 1 \bullet \bullet \mathrm{H} 4$ & 2.011 \\
\hline & $\mathrm{O} 1 \bullet \bullet \mathrm{H} 7$ & 2.185 \\
\hline & $\mathrm{O} 2 \bullet \bullet \mathrm{H} 6$ & 2.189 \\
\hline \multirow{5}{*}{ 1,3-IP } & $\mathrm{H} 1 \bullet \bullet H 2$ & 1.972 \\
\hline & $\mathrm{H} 1 \bullet \bullet \mathrm{H} 4$ & 2.017 \\
\hline & $\mathrm{O} 1 \bullet \bullet \mathrm{H} 7$ & 2.182 \\
\hline & $\mathrm{O} 2 \bullet \bullet \bullet \mathrm{H} 6$ & 2.190 \\
\hline & Interaction & $d(\AA)$ \\
\hline \multirow{2}{*}{$1,8-\mathrm{FP}$} & $\mathrm{H} 1 \bullet \bullet \mathrm{H}_{2}$ & 2.091 \\
\hline & $\mathrm{O} 1 \bullet \bullet \cdot \mathrm{H} 7 / \mathrm{O} 2 \bullet \bullet \bullet \mathrm{H} 8$ & 2.639 \\
\hline \multirow{6}{*}{$1,8-\mathrm{CP}$} & $\mathrm{H} 1 \bullet \bullet H 2$ & 2.362 \\
\hline & $\mathrm{H} 1 \bullet \bullet \mathrm{H} 3$ & 2.088 \\
\hline & $\mathrm{H} 1 \bullet \bullet \mathrm{H} 4$ & 2.218 \\
\hline & $\mathrm{H} 1 \bullet \bullet \mathrm{H} 5$ & 2.205 \\
\hline & $\mathrm{O} 1 \bullet \bullet \mathrm{H}_{7}$ & 2.881 \\
\hline & $\mathrm{O} 2 \bullet \bullet \mathrm{H} 8$ & 2.872 \\
\hline \multirow{2}{*}{$1,8-\mathrm{C}^{\prime} \mathrm{P}$} & $\mathrm{H} 1 \bullet \bullet \mathrm{H} 3 / \mathrm{H} 1 \bullet \bullet \mathrm{H}_{4}$ & 2.137 \\
\hline & $\mathrm{O} 1 \bullet \bullet \mathrm{H} 7 / \mathrm{O} 2 \bullet \bullet \mathrm{H}^{2}$ & 2.886 \\
\hline \multirow{2}{*}{$1,8-\mathrm{BP}$} & $\mathrm{H} 1 \bullet \bullet-H 2 / H 1 \bullet \bullet-H 4$ & 2.061 \\
\hline & $\mathrm{O} 1 \bullet \bullet \mathrm{H} 7 / \mathrm{O} 2 \bullet \bullet \bullet \mathrm{H} 8$ & 2.174 \\
\hline
\end{tabular}


Table S2. Calculated topological properties of the electron density for the intermolecular interaction in XPs.

\begin{tabular}{|c|c|c|c|c|c|}
\hline & Interactions & $\begin{array}{c}{ }^{\mathrm{a}} \mathrm{d}, \\
(\AA)\end{array}$ & $\begin{array}{c}{ }^{\mathrm{b}} \rho_{\mathrm{b}}(\mathrm{r}), \\
\left(\mathrm{e} \AA^{-3}\right)\end{array}$ & $\begin{array}{c}{ }^{\mathrm{c}} \nabla^{2} \rho_{\mathrm{b}}(\mathrm{r}), \\
\left(\mathrm{e} \AA^{-5}\right)\end{array}$ & $\begin{array}{c}{ }^{\mathrm{d}} \mathrm{DE}, \\
\left(\mathrm{kJmol}^{-1}\right)\end{array}$ \\
\hline $1,8-\mathrm{FP}$ & $\mathrm{F} 1 \cdots \mathrm{C} 38 / \mathrm{F} 2 \cdots \mathrm{C} 18$ & 3.145 & 0.035 & 0.538 & 4.27 \\
\hline $1,3-\mathrm{IP}$ & $\mathrm{I} 2 \cdots \mathrm{C} 21 / \mathrm{I} 2 \cdots \mathrm{C} 23$ & 3.405 & 0.066 & 0.675 & 7.38 \\
\hline $1,8-\mathrm{C}$ 'P & $\mathrm{H} 7 \cdots \mathrm{H} 16 / \mathrm{H} 8 \cdots \mathrm{H} 15$ & 2.165 & 0.042 & 0.504 & 4.25 \\
\hline \multirow{3}{*}{$1,8-\mathrm{BP}$} & $\mathrm{H} 10 \cdots \mathrm{H} 17 / \mathrm{H} 9 \cdots \mathrm{H} 18$ & 2.389 & 0.035 & 0.469 & 3.71 \\
\cline { 2 - 6 } & $\mathrm{H} 10 \cdots \mathrm{H} 18 / \mathrm{H} 9 \cdots \mathrm{H} 17$ & 2.524 & 0.029 & 0.418 & 3.30 \\
\cline { 2 - 6 } & $\mathrm{Br} 2 \cdots \mathrm{C} 20$ & 3.476 & 0.039 & 0.446 & 3.43 \\
\hline
\end{tabular}

${ }^{\mathrm{a}} \mathrm{d}=$ distance, ${ }^{\mathrm{b}} \rho_{\mathrm{b}}(\mathrm{r})=$ electron density at the $\mathrm{BCP},{ }^{\mathrm{c}} \nabla^{2} \rho_{\mathrm{b}}(\mathrm{r})=$ Laplacian of $\rho_{\mathrm{b}}(\mathrm{r})$ and ${ }^{\mathrm{d}} \mathrm{DE}=$ dissociation energy.

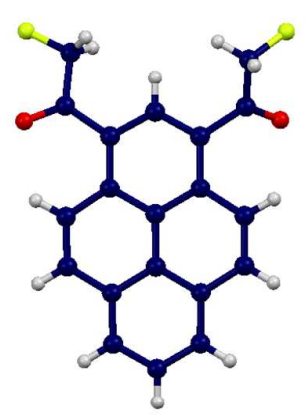

1,3-FP

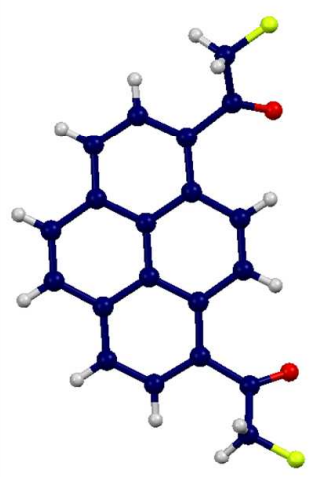

1,8-FP

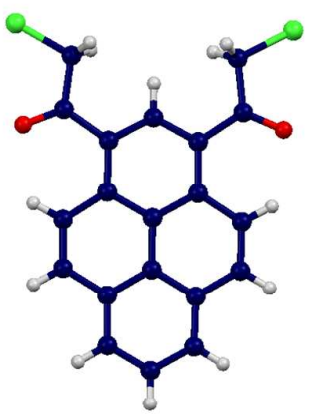

1,3-CP

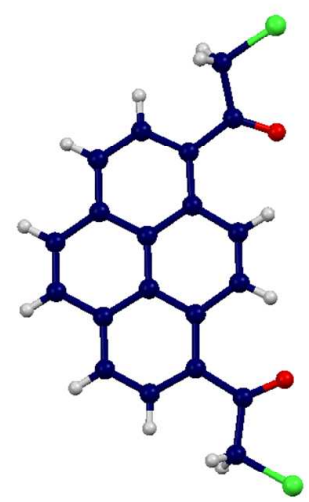

$1,8-C P$

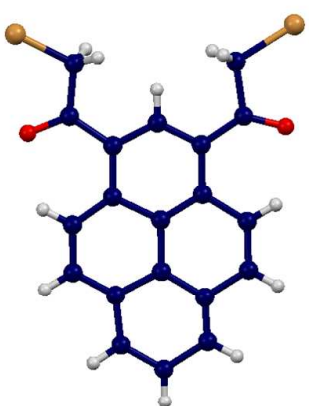

1,3-BP

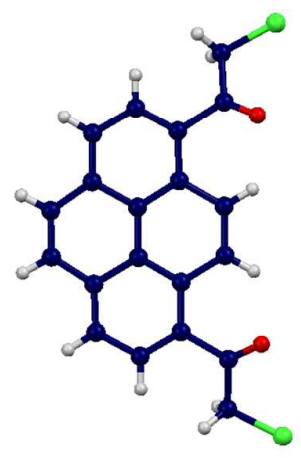

$1,8-C^{\prime} \mathbf{P}$

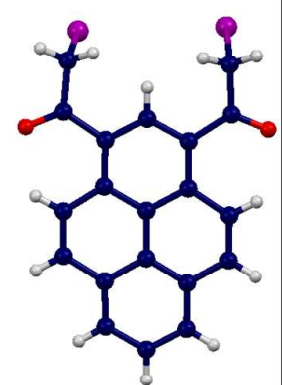

1,3-IP

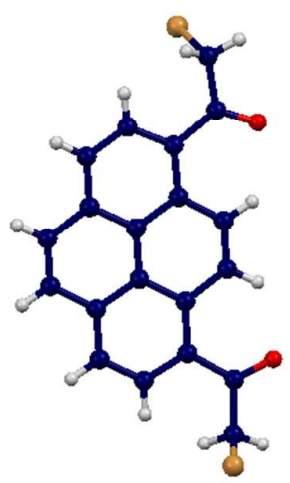

1,8-BP

Figure S1. Single crystal X-ray structure of XPs. 


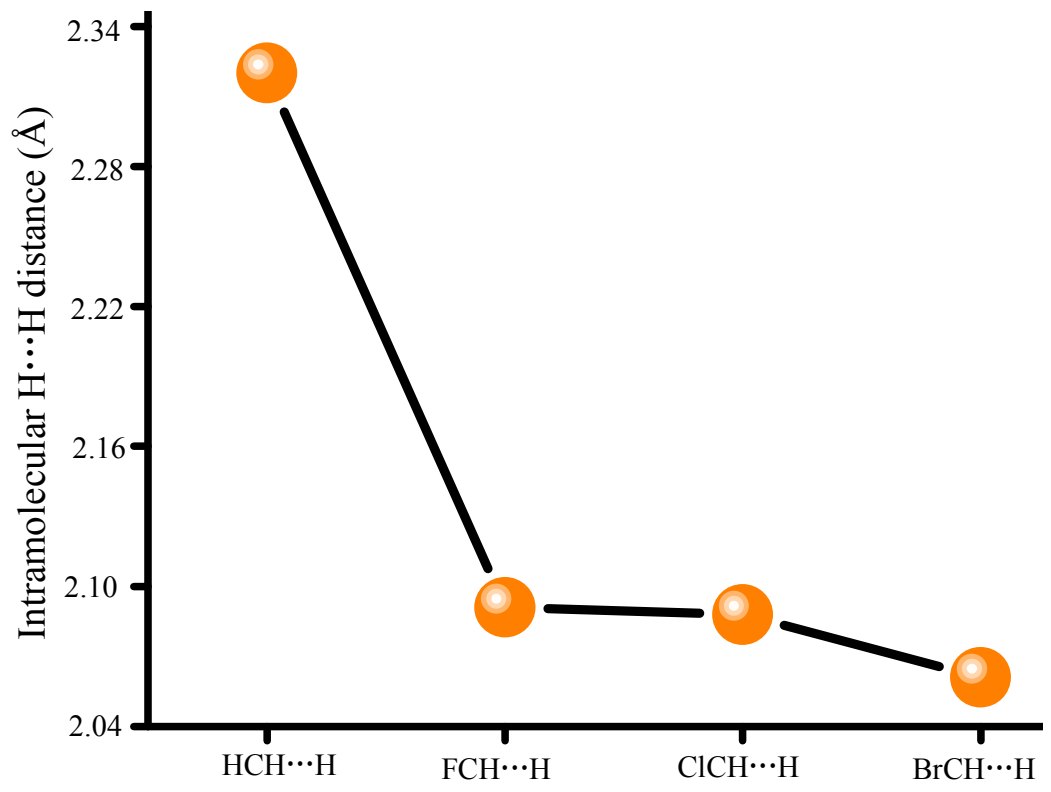

Figure S2. Decrease in the intramolecular dihydrogen distance in 1,8-XPs compared to 1,8-AP (value taken from ref. 2).

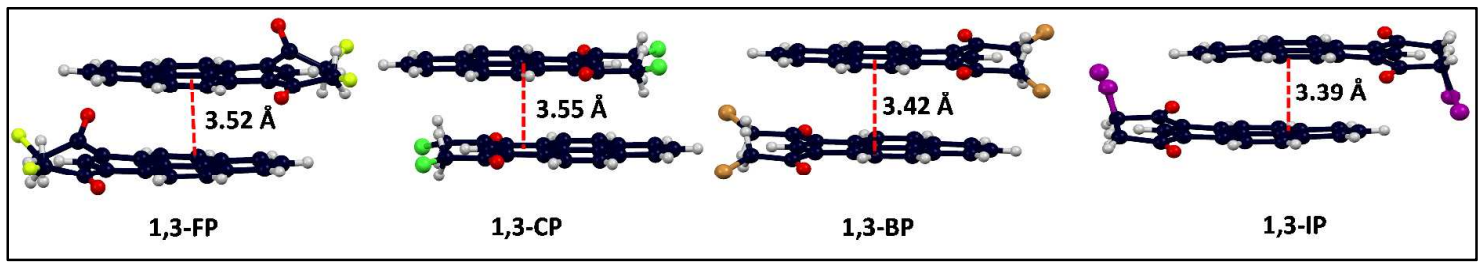

Figure S3. Shows the decrease in the interplanar distance between pyrene units in 1,3-XP. 
A)
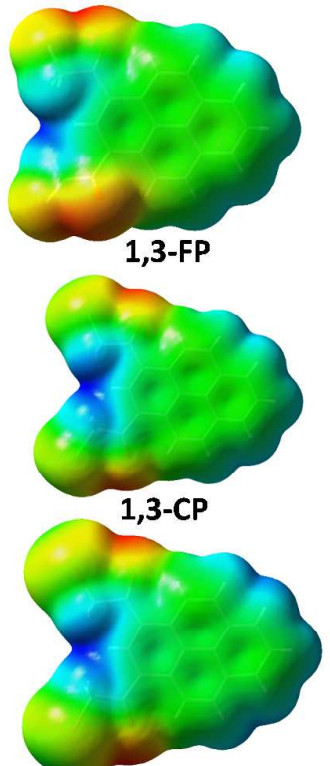

1,3-BP

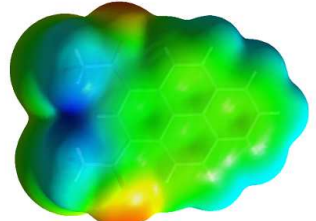

1,3-IP
B)
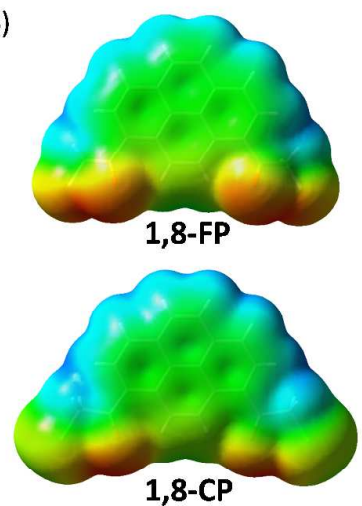

$1,8-\mathrm{CP}$
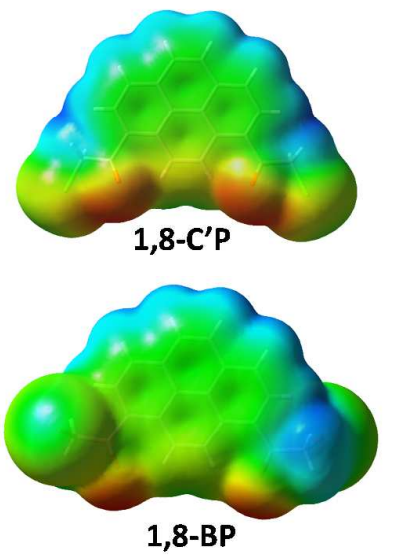

Figure S4. Calculated ESP maps of representative monomers of A) 1,3-XP and B) 1,8-XP from crystal structure. All maps used consistent surface potential ranges $[-4.75 \mathrm{e}-2$ au (red) to $4.75 \mathrm{e}-2 \mathrm{au}$ (blue)] and an isovalue of $0.000400 \mathrm{au}$.

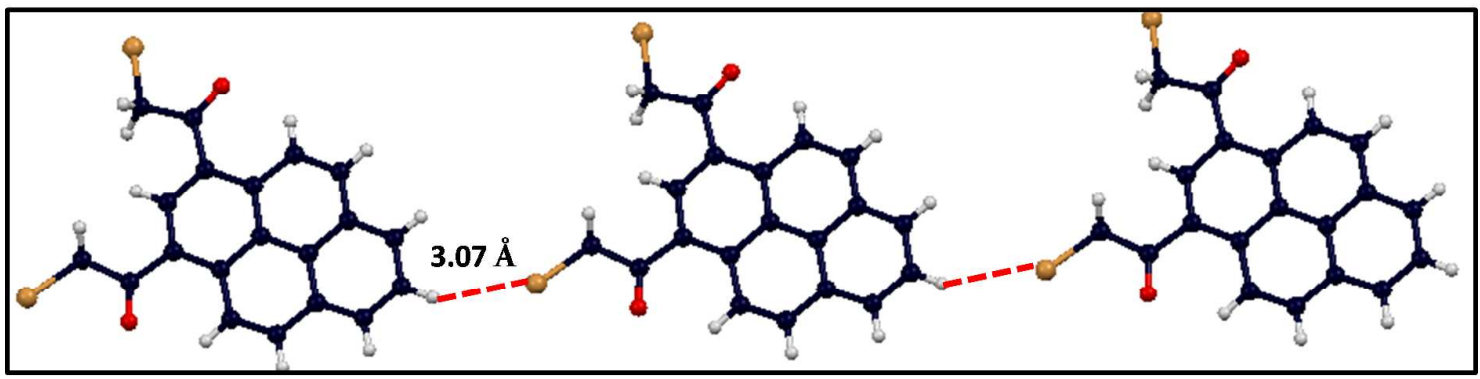

Figure S5. Intermolecular $\mathrm{C}\left(\mathrm{sp}^{2}\right)-\mathrm{H} \bullet \bullet B r$ interaction in 1,3-BP. 


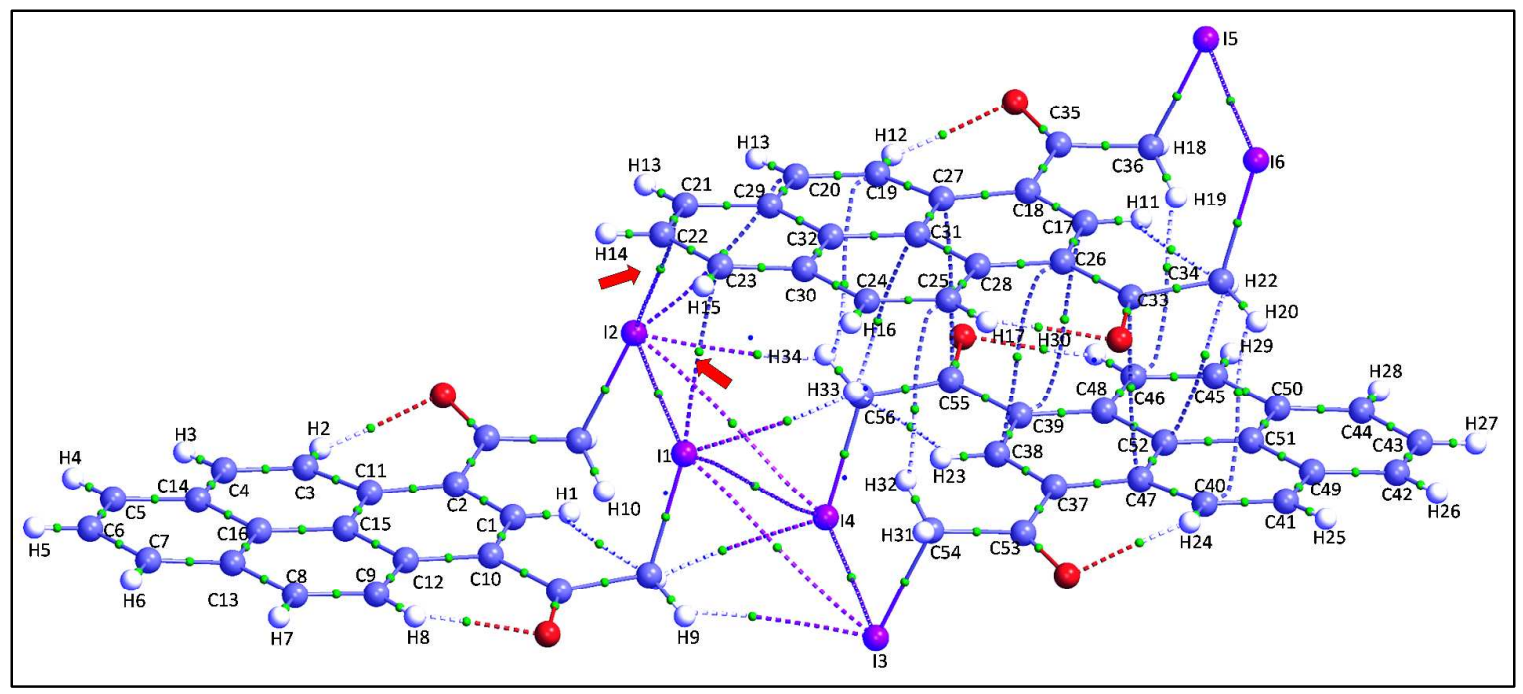

Figure S6. Shows QTAIM electron density map of 1,3-IP, arrows indicate the existence of intermolecular $\mathrm{I} \bullet \cdot \pi$ contacts.

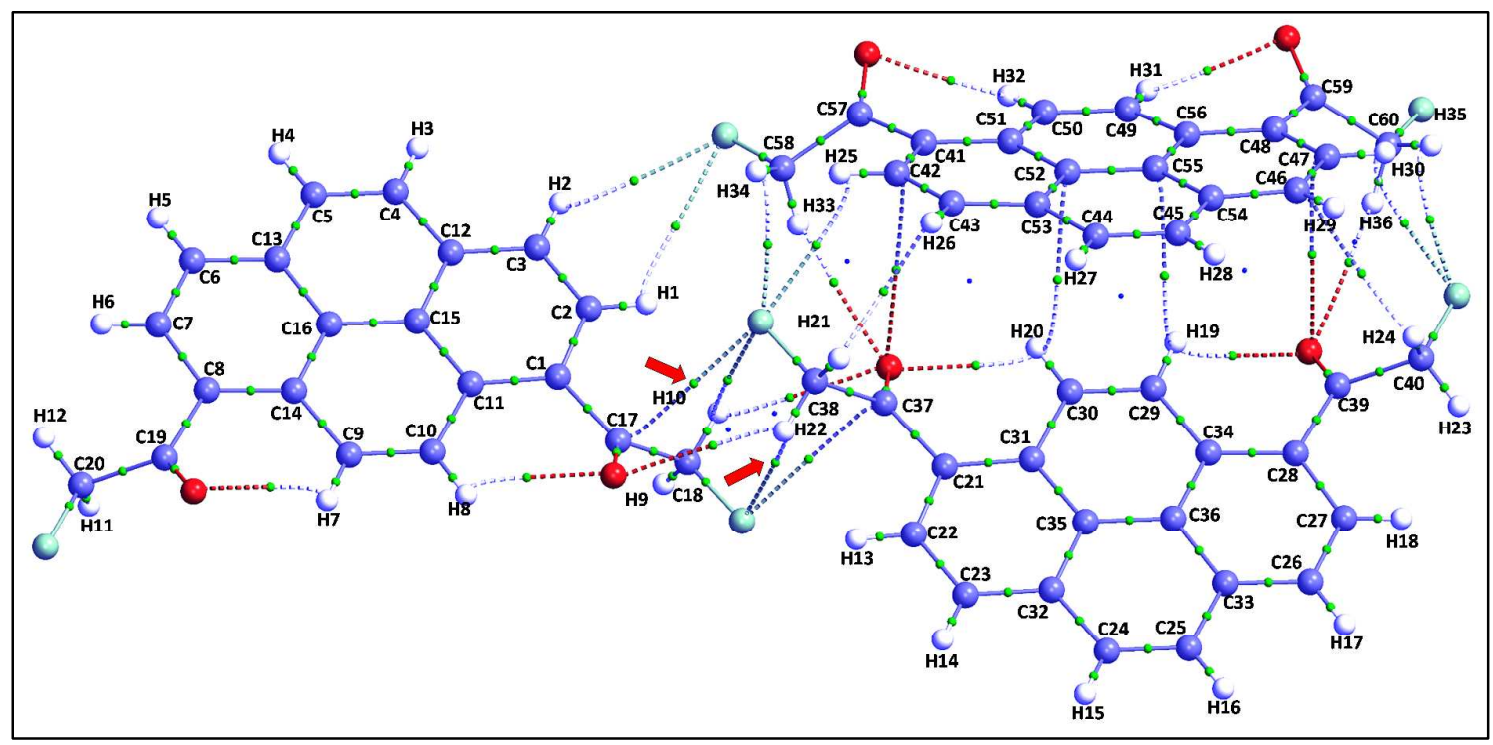

Figure S7. Shows QTAIM electron density map of 1,8-FP, arrows indicate the existence of intermolecular C...F interactions.

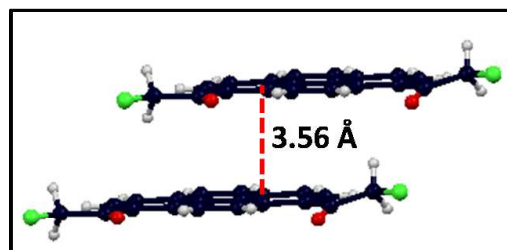

$1,8-\mathrm{CP}$

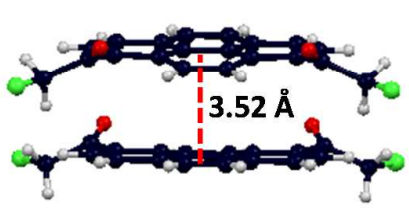

1,8-C'P

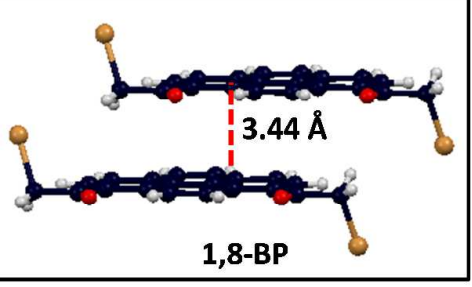

Figure S8. Shows the decrease in the interplanar distance between pyrene units in 1,8-XP. 


\section{Reference:}

1. Frisch, M. J.; Trucks, G. W.; Schlegel, H. B.; Scuseria, G. E.; Rob, M. A.; Cheeseman, J. R.; Montgomery Jr., J. A.; Vreven, T. K., K. N.; Burant, J. C.; Millam, J. M.; Iyengar, S. S.; Tomasi, J.; Barone, V.; Mennucci, B.; Cossi, M.; Scalmani, G.; Rega, N.; Petersson, G. A.; Nakatsuji, H.; Hada, M.; Ehara, M.; Toyota, K.; Fukuda, R.; Hasegawa, J.; Ishida, M.; Nakajima, Y.; Honda, O.; Kitao, H.; Nakai, M.; Klene, X.; Li, J. E.; Knox, H. P.; Hratchian, J. B.; Cross, T.; Bakken, V.; Adamo, C.; Jaramillo, J.; Gomperts, R.; Stratmann, R. E.; Yazyev, O.; Austin, A. J.; Cammi, R.; Pomelli, C.; Ochterski, J. W.; Ayala, P. Y.; Morokuma, K.; Voth, G. A.; Salvador, P.; Dannenberg, J. J.; Zakrzewski, V. G.; Dapprich, S.; Daniels, A. D.; Strain, M. C.; Farkas, O.; Malick, D. K.; Rabuck, A. D.; Raghavachari, K.; Foresman, J. B.; Ortiz, J. V.; Cui, Q.; Baboul, A. G.; Clifford, S.; Cioslowski, J.; Stefanov, B. B.; Liu, G.; Liashenko, A.; Piskorz, P.; Komaromi, I.; Martin, R. L.; Fox, D. J.; Keith, T.; Al-Laham, M. A.; Peng, C. Y.; Nanayakkara, A.; Challacombe, M.; Gill, P. M. W.; Johnson, B.; Chen, W.; Wong, M. W.; Gonzalez, C.; Pople, J. A.; (Gaussian, Inc., Wallingford, CT, 2003).

2. Rajagopal, S. K.; Philip, A. M.; Nagarajan, K.; Hariharan, M. Chem. Commun. 2014, 50, 8644. 